\title{
Bi-Functionalized Intrinsically Microporous Polyimides with Simultaneously Enhanced Gas Permeability and Selectivity
}

Xiaohua Ma, Mohsin Mukaddam, Ingo Pinnau*

Xiaohua Ma, Mohsin Mukaddam, Ingo Pinnau.

King Abdullah University of Science and Technology (KAUST), Advanced Membranes and

Porous Materials Center (AMPMC), Division of Physical Sciences and Engineering, Chemical and Biological Engineering Program, Thuwal, 23955, KSA.

E-mail: Ingo.Pinnau@kaust.edu.sa 
Two novel intrinsically microporous co-polyimides, synthesized by condensation reaction of 4,4'-(hexafluoroisopropylidene) diphthalic anhydride (6FDA), 3,3,3',3'-tetramethyl-1,1'spirobisindane-5,5'-diamino-6,6'-diol (SBIDA) and 3,5-diaminobenzoic acid (DABA) with diamine ratios of 80-20 (Co-80/20) and 50-50 (Co-50/50) are reported. Unexpectedly, the Co$80 / 20$ not only demonstrated higher microporosity $\left(300 \mathrm{~m}^{2} / \mathrm{g}\right)$ than the PIM-6FDA-OH homopolymer $\left(190 \mathrm{~m}^{2} / \mathrm{g}\right)$, but exhibited simultaneously enhanced $\mathrm{CO}_{2}$ permeability (from 119 to 171 Barrer) and $\mathrm{CO}_{2} / \mathrm{CH}_{4}$ selectivity (from 35 to 41 ) after thermal annealing at $250{ }^{\circ} \mathrm{C}$. This higher permeability originated from enhanced diffusivity $\left(\mathrm{D}_{\mathrm{CO} 2}\right)$ and the higher selectivity resulted from its increased diffusion selectivity $\left(D_{\mathrm{CO} 2} / D_{\mathrm{CH} 4}\right)$. After crosslinking at $300{ }^{\circ} \mathrm{C}$, the $\mathrm{Co}-80 / 20$ exhibited an even higher $\mathrm{CO}_{2}$ permeability (261 Barrer) and almost unchanged $\mathrm{CO}_{2} / \mathrm{CH}_{4}$ selectivity. 


\section{Introduction}

Polymer membranes are applied in a variety of industrial applications, such as hydrogen recovery in ammonia plants, on-site nitrogen generation from air, and natural gas sweetening, etc. ${ }^{[1-2]}$ Currently, only around ten polymers are used in $90 \%$ of the membrane-based gas separation market. ${ }^{[3]}$ Highly efficient membranes are especially demanding for further costeffectiveness. However, the gas permeation properties of polymer membranes are typically restricted to a permeability/selectivity trade-off, first proposed by Robeson, and later theoretically analyzed by Freeman; that is, polymers with high permeability exhibit low selectivity and vice versa. ${ }^{[4-6]}$ Rational molecular design is an efficient way to improve the gas transport performance of advanced polymer membranes. The concept of introducing micropores $(<20 \AA)$ or ultramicropores $(<7 \AA)$ into rigid polymer structures by incorporation of bulky sites of contortion to form solution-processable ladder polymers of intrinsic microporosity (PIM) was first reported by Budd's and McKeown's groups in 2004. ${ }^{[7,8]}$ The corresponding PIM-1 demonstrated several orders higher permeability combined with modest selectivity as compared with conventional polymers. ${ }^{[9]}$ Thereafter, extensive investigations were performed on pristine and modified PIM-1 as well as structurally novel PIMs. ${ }^{[10-17]}$ Significant progress in the development of high-performance PIMs has been achieved for triptycene- and Tröger's base-based ladder PIMs, as their performance defines the 2015 upper bounds for $\mathrm{O}_{2} / \mathrm{N}_{2}, \mathrm{H}_{2} / \mathrm{N}_{2}$ and $\mathrm{H}_{2} / \mathrm{CH}_{4}{ }^{[17]}$

The introduction of intrinsic microporosity was successfully extended to polyimides by incorporating various contortion sites (e.g., spirobisindane, ethanoanthrance, spirobifluorene, triptycene and Tröger's base) to dianhydride or diamine building blocks. Some recently designed PIM-PIs exhibited extraordinary gas separation performance and reached the 2015 upper bound for several gas pairs. ${ }^{[18-23]}$ In addition, $o$-hydroxy-functionalized spirobisindaneand spirobifluorene-based PIM-PIs were designed to combine the properties of highly permeable PIMs and highly selective hydroxy-containing polyimides. ${ }^{[24,25]}$ Such hydroxy- 
functionalized PIM-PIs demonstrated high $\mathrm{CO}_{2} / \mathrm{CH}_{4}$ selectivity (from 29 to 42) and $\mathrm{CO}_{2}$ permeability about 10-25 fold higher than that of commercial membrane materials such as cellulose acetate.

Co-polyimides functionalized with carboxylic acid groups exhibit a good combination of permeability and selectivity and have shown advantages against physical aging and plasticization under aggressive high-pressure natural gas feed after solid-state crosslinking. ${ }^{[26-}$

${ }^{33]}$ Koros' group reported copolymers made from 6FDA, DABA and benzene-1,3-diamine or 2,4,6-trimethylbenzene-1,3-diamine. After crosslinking with different glycols at medium temperature $\left(\sim 200{ }^{\circ} \mathrm{C}\right)$, the resulting polymers exhibited enhanced permeability and slightly increased selectivity, combined with a remarkable plasticization resistance. ${ }^{[31,32]}$ In this study, we report for the first time bifunctional intrinsically microporous co-polyimides containing both $\mathrm{OH}$ and $\mathrm{COOH}$ groups. The structures of the polymers and their synthetic procedure are shown in Figure 1.

\section{$<$ Figure 1 >}

\section{Results and Discussion}

The PIM homopolymers and copolymers were synthesized by condensation reaction of 6FDA, SBIDA $^{[24]}$ and DABA in $m$-cresol with catalytic amount of isoquinoline at $180{ }^{\circ} \mathrm{C}$ for several hours. The detailed synthesis and characterization of the homopolymers and copolymers are shown in the supporting information. By changing the diamine ratio, pure PIM-6FDA-OH, Co-80/20 (SBIDA to DABA ratio of 80/20), Co-50/50 (SBIDA to DABA ratio of 50/50), and pure 6FDA-DABA were obtained. The copolymer structures and the monomer ratio were confirmed and identified by NMR as shown in Figure 1, as evidenced by a clear peak of the $\mathrm{COOH}$ group at $13.6 \mathrm{ppm}$ and $\mathrm{OH}$ group at $9.6 \mathrm{ppm}$. The physical properties of the 
polyimides are shown in Table 1. Information about the densities of PIM-6FDA-OH, Co80/20 and Co-50/50 before and after heat-treatment is provided in Table S1.

\section{$<$ Table 1>}

All polymers exhibited excellent thermal stability as shown in Figure 2. The online mass spectroscopy (MS) of the Co-80/20 polyimide was very similar to that of PIM-6FDA-OH, ${ }^{[24]}$ characterized by a $\mathrm{CO}_{2}$ and $\mathrm{H}_{2} \mathrm{O}$ peak around 430 to $510{ }^{\circ} \mathrm{C}$, respectively (Figure 1a). The decomposition of the Co-50/50 polyimide was more complex due to multi-decomposition stages. It is noteworthy that $\sim 1.5 \%$ weight loss of water, as confirmed by online MS, was observed in the TGA curve around $290{ }^{\circ} \mathrm{C}$ (Figure $\mathbf{2 b}$ ). This weight loss is very close to the theoretical weight loss of $1.37 \%$, caused by the in-situ solid-state esterification reaction of $\mathrm{OH}$ (from SBIDA) and COOH (from DABA), respectively. Importantly, unlike PIM-6FDA-OH, the Co-80/20 and Co-50/50 polyimides could not be dissolved in any solvent after treatment at $300{ }^{\circ} \mathrm{C}$ for $1 \mathrm{hr}$ under $\mathrm{N}_{2}$ atmosphere (Table S2), providing evidence of crosslinking. Previous work reported a self-crosslinking reaction of copolymers containing only DABA to form anhydride, which occurred at or above $330{ }^{\circ} \mathrm{C}$ for more than $20 \mathrm{hrs}{ }^{[29]}$

\section{$<$ Figure 2>}

All polymer membranes were treated under two different conditions, that is, $250{ }^{\circ} \mathrm{C}$ annealed under vacuum for $24 \mathrm{hrs}$ and $300{ }^{\circ} \mathrm{C}$ heat-treated under $\mathrm{N}_{2}$ atmosphere for $1 \mathrm{hr}$. It is noteworthy that all polymers annealed at $250{ }^{\circ} \mathrm{C}$ under vacuum were soluble in NMP and DMF (Table S2).

Unexpectedly, the bi-functionalized Co-80/20 polyimide exhibited distinctly higher $\mathrm{N}_{2}$ BET surface area compared with PIM-6FDA-OH (Figure 2c). The Co-80/20 polyimide 
demonstrated a remarkable $\sim 50 \%$ enhancement in the BET surface area to $300 \mathrm{~m}^{2} / \mathrm{g}$ from 190 $\mathrm{m}^{2} / \mathrm{g}$ for PIM-6FDA-OH. This may due to the incorporation of the DABA moiety which may give rise to extra hydrogen bonding ( $\mathrm{V}$-shaped hydrogen bond compared with linear hydrogen bond in PIM-6FDA-OH, Figure 2e) in either intra- or inter-molecular chains between the $\mathrm{COOH}$ (from DABA) and $\mathrm{OH}$ group (from SBIDA), which created additional free volume. However, the Co-50/50 polyimide exhibited very low porosity, possibly due to: (i) smaller contortion center density and (ii) excessive hydrogen bonding compromising the micropore formation ability. It is noteworthy that after heat-treatment of the copolymers to $300{ }^{\circ} \mathrm{C}$ no hysteresis in the $\mathrm{N}_{2}$ sorption isotherms of the pristine and crosslinked copolymers were observed, as shown in Figure 2d.

The pure-gas permeability of $\mathrm{H}_{2}, \mathrm{~N}_{2}, \mathrm{O}_{2}, \mathrm{CH}_{4}$ and $\mathrm{CO}_{2}$ was determined by the constantvolume/variable-pressure method and the results are summarized in Table 2 . The $250{ }^{\circ} \mathrm{C}$ annealed PIM-6FDA-OH homopolymer demonstrated a lower $\mathrm{CO}_{2}$ permeability (119 vs 265 Barrer) but higher $\mathrm{CO}_{2} / \mathrm{CH}_{4}$ selectivity (35 vs 29) compared with the same polymer membrane treated at $120{ }^{\circ} \mathrm{C} .{ }^{[24]}$ Surprisingly, the Co-80/20 polyimide treated at $250{ }^{\circ} \mathrm{C}$ demonstrated both higher permeability and selectivity for several gas pairs than the PIM6FDA-OH, e.g., the permeability of $\mathrm{CO}_{2}$ increased over 50\% from 119 to 173 Barrer and the selectivity of $\mathrm{CO}_{2} / \mathrm{CH}_{4}$ was enhanced from 35 to 42 . This performance is an improvement compared to previously reported DABA-containing polyimides such as 6FDA-DAM:DABA $(3: 2)$ treated at $180{ }^{\circ} \mathrm{C}$ for $24 \mathrm{hrs}\left(\mathrm{P}_{\mathrm{CO} 2}=144 \text { Barrer, } \alpha_{\mathrm{CO} 2 / \mathrm{CH} 4}=34.4\right)^{[29]}$ and $6 \mathrm{FDA}-$ 6FpDA:DABA $(2: 1)\left(\mathrm{P}_{\mathrm{CO} 2}=34\right.$ Barrer, $\left.\alpha_{\mathrm{CO} 2 / \mathrm{CH} 4}=45\right) .{ }^{[31]}$ The Co-50/50 polyimide exhibited about the same $\mathrm{H}_{2}$ permeability (171 Barrer) as PIM-6FDA-OH (181 Barrer) but its $\mathrm{H}_{2} / \mathrm{CH}_{4}$ selectivity increased to 118 as compared to 53 for the homopolymer.

\section{<Table 2>}


The gas permeability results of the $300{ }^{\circ} \mathrm{C}$ crosslinked Co- $80 / 20$ and Co-50/50 polyimides are also summarized in Table 2. Higher temperature $\left(300{ }^{\circ} \mathrm{C}\right)$ and shorter thermal treatment time $(1 \mathrm{hr})$ resulted in higher permeability coupled with a slightly lower selectivity. For example, the $300{ }^{\circ} \mathrm{C}$ crosslinked Co- $80 / 20$ membrane demonstrated a further enhancement of $\mathrm{CO}_{2}$ permeability from 173 to 261 Barrer compared with the $250{ }^{\circ} \mathrm{C}$ annealed co-polyimide, while the $\mathrm{CO}_{2} / \mathrm{CH}_{4}$ selectivity of $\sim 40$ was essentially unaffected. This result is very promising as the performance for $\mathrm{CO}_{2} / \mathrm{CH}_{4}$ separation lies very close to the 2008 Robeson upper bound (Figure S1). It is also notable that the copolymer crosslinked at $300{ }^{\circ} \mathrm{C}$ demonstrated very stable performance after aging for more than one month. Only $10 \%$ permeability drop was observed coupled with a slight increase in selectivity (Table S3).

To better understand the effect of introducing DABA on the $\mathrm{CO}_{2} / \mathrm{CH}_{4}$ gas transport properties of OH-functionalized PIM-PI copolymers, the solubility coefficients of the membranes were measured by gravimetric sorption and the diffusion coefficients were then obtained by applying the relationship: $D=P / S$. The results are summarized in Table $\mathbf{S 4}$. The Co-80/20 polyimide membrane annealed at $250{ }^{\circ} \mathrm{C}$ demonstrated both higher permeability and selectivity than the PIM-6FDA-OH homopolymer. The major contribution to the higher permeability originated from its enhanced diffusion coefficient, that is, the diffusion coefficient of $\mathrm{CO}_{2}$ increased by $56 \%$ from $5.56 \times 10^{-8}$ to $8.69 \times 10^{-2} \mathrm{~cm}^{2} / \mathrm{s}$, which follows the trend of increased BET surface area of the Co-80/20 polyimide. Concurrently, the increase in $\mathrm{CO}_{2} / \mathrm{CH}_{4}$ permselectivity from 35 to 42 resulted from an increase in the diffusion selectivity ( $D_{\mathrm{CO} 2} / D_{\mathrm{CH} 4}$ increased from 9.6 to 11.3$)$. This was probably caused by hydrogen bonding between the $\mathrm{OH}$ group of SBIDA and $\mathrm{COOH}$ group of DABA (Figure 2e), where V-type hydrogen bonding sites created a stronger size-sieving effect compared with the linear hydrogen bonding in PIM-6FDA-OH.

The Co-50/50 polyimide showed a lower permeability than PIM-6FDA-OH due to a decrease in diffusion coefficient from $5.56 \times 10^{-8}$ to $3.87 \times 10^{-8} \mathrm{~cm}^{2} / \mathrm{s}$. It is suggested that 
hydrogen bonding and a lower spiro-center concentration resulted in tighter polymer chain packing, and, hence, lower diffusion coefficient and permeability.

\section{Conclusions}

Two bi-functionalized PIM-PIs were obtained by co-polymerization of 6FDA with SBIDA and DABA with different monomer ratios (80/20 and 50/50). These polyimides demonstrated

good solubility and high thermal stability. Compared with the PIM-6FDA-OH homopolymer, the Co-80/20 polyimide demonstrated not only larger BET surface area but also higher $\mathrm{CO}_{2}$ permeability and $\mathrm{CO}_{2} / \mathrm{CH}_{4}$ selectivity. The higher $\mathrm{CO}_{2}$ permeability resulted from an enhanced diffusion coefficient and the higher $\mathrm{CO}_{2} / \mathrm{CH}_{4}$ permselectivity originated from a higher diffusion selectivity $\left(\alpha_{\mathrm{D}}\right)$. The Co-50/50 polyimide exhibited higher selectivity than the PIM-6FDA-OH due to enhanced diffusion selectivity $\left(\alpha_{\mathrm{D}}\right)$.

\section{Supporting Information}

Details of the polymer synthesis, membrane formation procedure, polymer density, solubility of the polymers, gravimetric gas sorption, permeation data for aged $300{ }^{\circ} \mathrm{C}$ treated copolymers and the $\mathrm{CO}_{2} / \mathrm{CH}_{4}$ and $\mathrm{H}_{2} / \mathrm{CH}_{4}$ performance curves are provided in the supporting information. The Supporting Information is available from the Wiley Online Library or from the corresponding author.

Acknowledgements: The research reported in this publication was supported by funding from King Abdullah University of Science and Technology (KAUST).

Keywords: intrinsic microporous polymer; polyimide; crosslinking; hydrogen bonding; gas separation 
[1] P. Bernardo, E. Drioli and G. Golemme, Ind. Eng. Chem. Res. 2009, 48, 4638.

[2] R. W. Baker and K. Lokhandwala, Ind. Eng. Chem. Res. 2008, 47, 2109.

[3] R. W. Baker and B. T. Low, Macromolecules 2014, 47, 6999.

[4] L. M. Robeson, J. Membr. Sci. 1991, 62, 165.

[5] L. M. Robeson, J. Membr. Sci. 2008, 320, 390.

[6] B. D. Freeman, Macromolecules 1999, 32, 375.

[7] P. M. Budd, E. S. Elabas, B. S. Ghanem, S. Makhseed, N. B. McKeown, K. J. Msayib, C. E. Tattershall and D. Wang, Adv. Mater. 2004, 16, 456.

[8] P. M. Budd, B. S. Ghanem, S. Makhseed, N. B. McKeown, K. J. Msayib and C. E. Tattershall, Chem. Commun. 2004, 230.

[9] P. M. Budd, K. J. Msayib, C. E. Tattershall, B. S. Ghanem, K. J. Reynolds, N. B. McKeown and D. Fritsch, J.Membr. Sci. 2005, 251, 263.

[10] N. Y. Du, G. P. Robertson, I. Pinnau and M. D. Guiver, Macromolecules 2009, 42, 6023.

[11] N. Du, H. B. Park, G. P. Robertson, M. M. Dal-Cin, T. Visser, L. Scoles and M. D. Guiver, Nat. Mater. 2011, 10, 372.

[12] Q. L. Song, S. Cao, R. H. Pritchard, B. Ghalei, S. A. Al-Muhtaseb, E. M. Terentjev, A. K. Cheetham and E. Sivaniah, Nat. Commun. 2014, 5.

[13] C. G. Bezzu, M. Carta, A. Tonkins, J. C. Jansen, P. Bernardo, F. Bazzarelli and N. B. McKeown, Adv. Mater. 2012, 24, 5930.

[14] M. Carta, P. Bernardo, G. Clarizia, J. C. Jansen and N. B. McKeown, Macromolecules 2014, 47, 8320.

[15] B. S. Ghanem, R. Swaidan, X. H. Ma, E. Litwiller and I. Pinnau, Adv. Mater. 2014, 26, 6696.

[16] M. Carta, R. Malpass-Evans, M. Croad, Y. Rogan, J. C. Jansen, P. Bernardo, F. Bazzarelli and N. B. McKeown, Science 2013, 339, 303.

[17] R. Swaidan, B. Ghanem and I. Pinnau, ACS Macro Letters, 2015, 947-951.

[18] B. S. Ghanem, N. B. McKeown, P. M. Budd, J. D. Selbie and D. Fritsch, Adv. Mater. 2008, 20, 2766.

[19] Y. Rogan, L. Starannikova, V. Ryzhikh, Y. Yampolskii, P. Bernardo, F. Bazzarelli, J. C. Jansen and N. B. McKeown, Polym. Chem. 2013, 4, 3813.

[20] Y. Rogan, R. Malpass-Evans, M. Carta, M. Lee, J. C. Jansen, P. Bernardo, G. Clarizia, E. Tocci, K. Friess, M. Lanč and N. B. McKeown, J. Mater. Chem. A 2014, 2, 4874.

[21] X. H. Ma, B. Ghanem, O. Salines, E. Litwiller and I. Pinnau, Acs Macro Lett. 2015, 4, 231.

[22] B. S. Ghanem, R. Swaidan, E. Litwiller and I. Pinnau, Adv. Mater. 2014, 26, 3688.

[23] Z. G. Wang, D. Wang and J. Jin, Macromolecules 2014, 47, 7477.

[24] X. Ma, R. Swaidan, Y. Belmabkhout, Y. Zhu, E. Litwiller, M. Jouiad, I. Pinnau and Y. Han, Macromolecules 2012, 45, 3841.

[25] X. H. Ma, O. Salinas, E. Litwiller and I. Pinnau, Polym. Chem. 2014, 5, 6914. 
[26] C. Staudt-Bickel and W. J. Koros, J. Membr. Sci. 1999, 155, 145.

[27] J. H. Kim, W. J. Koros and D. R. Paul, J. Membr. Sci. 2006, 282, 21.

[28] L. L. Cui, W. L. Qiu, D. R. Paul and W. J. Koros, Polymer 2011, 52, 5528.

[29] W. L. Qiu, C. C. Chen, L. R. Xu, L. L. Cui, D. R. Paul and W. J. Koros, Macromolecules 2011, 44, 6046.

[30] W. L. Qiu, K. Zhang, F. S. Li, K. Zhang and W. J. Koros, Chemsuschem 2014, 7, 1186.

[31] J. D. Wind, C. Staudt-Bickel, D. R. Paul and W. J. Koros, Ind. Eng. Chem. Res. 2002, 41, 6139.

[32] A. M. W. Hillock and W. J. Koros, Macromolecules 2007, 40, 583.

[33] J. D. Wind, C. Staudt-Bickel, D. R. Paul and W. J. Koros, Macromolecules 2003, 36, 1882. 
Figure 1.
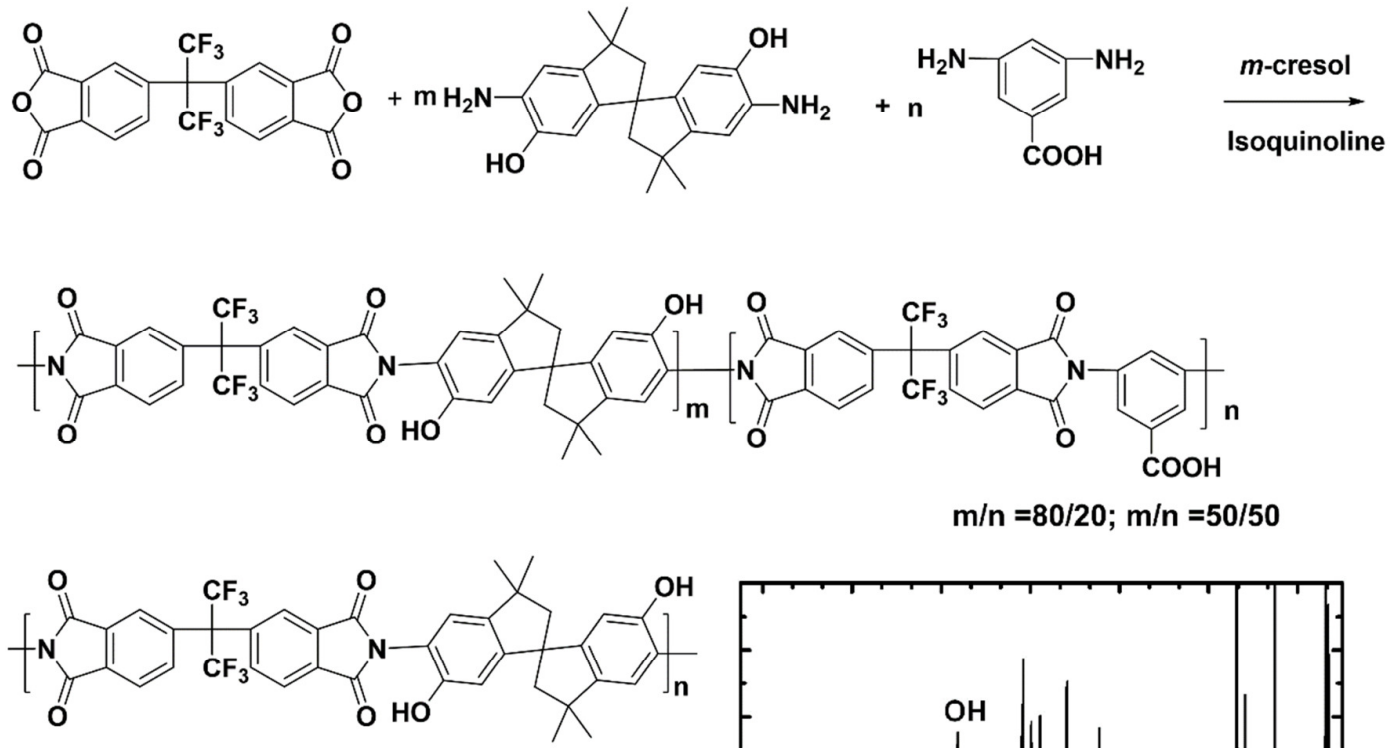

PIM-6FDA-OH


Figure 1. Synthetic procedure and the structures of the homo- and co-polyimides (PIM6FDA-OH, 6FDA-DABA, Co-80/20 and Co-50/50), as well as the ${ }^{1} \mathrm{H}$ NMR of the copolyimides. 
Figure 2.
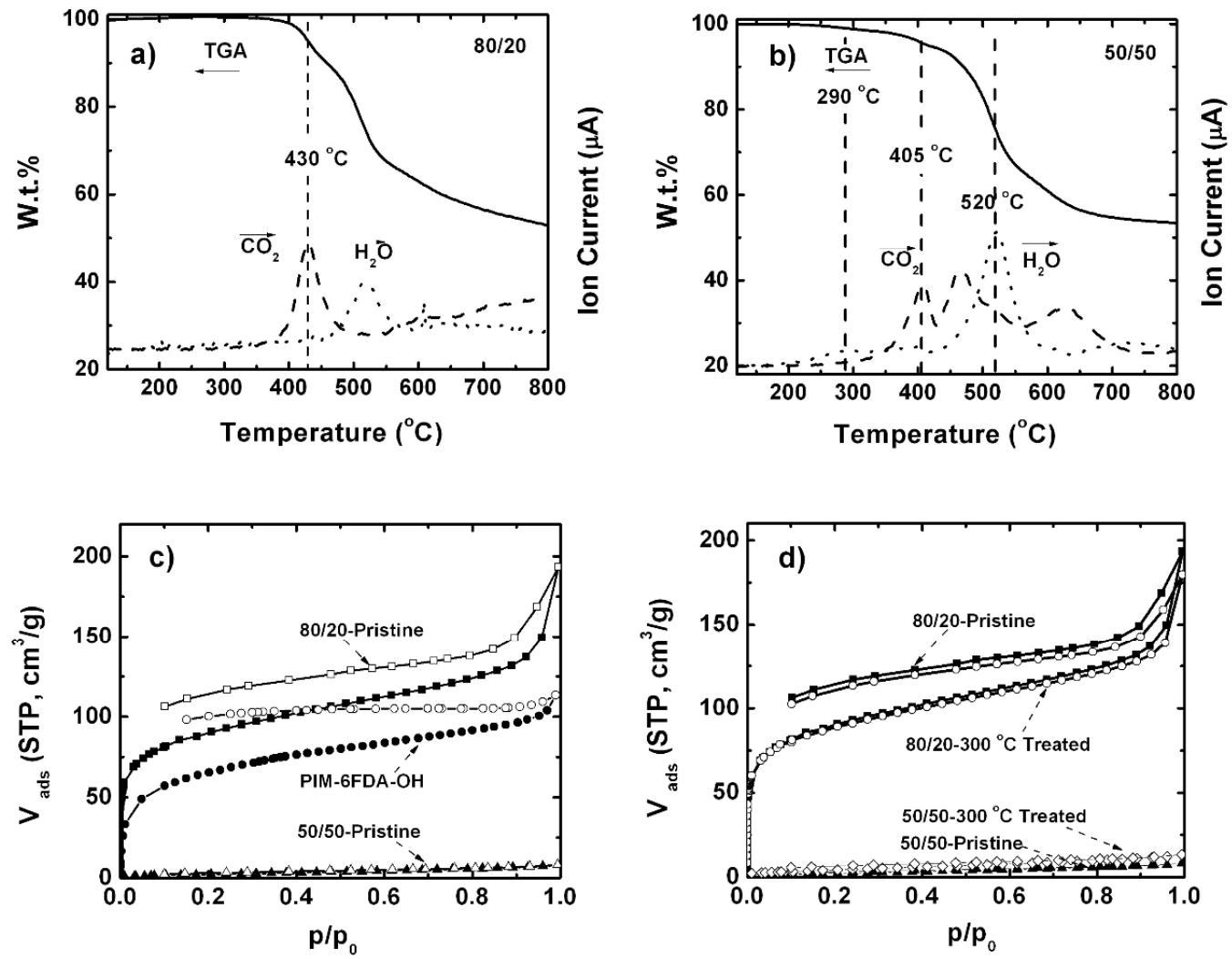

e)

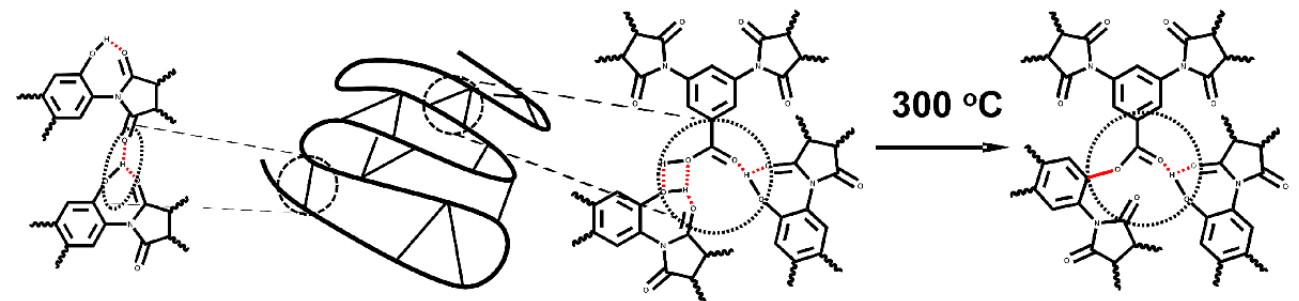

Figure 2. a) TGA-QMS of the Co-80/20 polyimide; b) TGA-QMS of the Co-50/50 polyimide; both membranes were heated to $800{ }^{\circ} \mathrm{C}$ at $3{ }^{\circ} \mathrm{C} /$ min under $\mathrm{N}_{2}$ atmosphere; c) $\mathrm{N}_{2}$ adsorption/desorption isotherms of $250{ }^{\circ} \mathrm{C}$ treated PIM-6FDA-OH, Co-80/20, and Co50/50 polyimides; d) $\mathrm{N}_{2}$ adsorption/desorption isotherms of the pristine and $300{ }^{\circ} \mathrm{C}$ treated Co-80/20 and Co-50/50 co-polyimides; e) proposed structure of hydrogen bonding and crosslinking reaction in the bi-functionalized PIM-PIs. 
Table 1. Basic properties of the homo and co-polyimides.

\begin{tabular}{lcccc}
\hline Polymers & $\mathbf{M}_{\mathbf{n}} \times \mathbf{1 0}^{\mathbf{4}}(\mathbf{g} / \mathbf{m o l}){ }^{\text {a) }}$ & PDI & $\mathbf{T}_{\mathbf{d}}\left({ }^{\mathbf{0}} \mathbf{C}\right)^{\mathrm{c})}$ & $\mathbf{S}_{\mathbf{B E T}}\left(\mathbf{m}^{\mathbf{2}} / \mathbf{g}\right)$ \\
\hline PIM-6FDA-OH $^{\text {b) }}$ & 8.54 & 1.94 & 380 & 190 \\
Co-80/20 & 3.52 & 1.65 & 380 & 300 \\
Co-50/50 & 4.00 & 1.68 & 300 & 9 \\
6FDA-DABA & 3.26 & 3.6 & 380 & -
\end{tabular}

${ }^{\text {a) }}$ Measured by GPC using THF as solvent and polystyrene as external standard. ${ }^{\text {b) }}$ Data from reference 24, except BET surface area which was determined with $\mathrm{N}_{2}$ in this study ${ }^{\mathrm{c})}$ Onset decomposition temperature from the TGA curve.

Table 2. Permeability and ideal selectivity of the polyimides and co-polyimides heat-treated under different conditions.

\begin{tabular}{|c|c|c|c|c|c|c|c|c|c|}
\hline \multirow{2}{*}{ Polymer } & \multicolumn{5}{|c|}{ Permeability (Barrer) } & \multicolumn{4}{|c|}{ Ideal selectivity $\left(\alpha_{\mathrm{X} / \mathrm{Y}}\right)$} \\
\hline & $\mathbf{H}_{2}$ & $\mathbf{N}_{2}$ & $\mathbf{O}_{2}$ & $\mathrm{CH}_{4}$ & $\mathrm{CO}_{2}$ & $\mathbf{H}_{2} / \mathbf{N}_{2}$ & $\mathrm{H}_{2} / \mathrm{CH}_{4}$ & $\mathbf{O}_{2} / \mathbf{N}_{2}$ & $\mathrm{CO}_{2} / \mathrm{CH}_{4}$ \\
\hline PIM-6FDA-OH ${ }^{\text {a) }}$ & 181 & 5.5 & 23.8 & 3.4 & 119 & 33 & 53 & 4.3 & 35 \\
\hline $\mathrm{Co}-80 / 20^{\text {a) }}$ & 285 & 6.8 & 32.6 & 4.1 & 173 & 42 & 70 & 4.8 & 42 \\
\hline $\mathrm{Co}-50 / 50^{\text {a) }}$ & 171 & 2.85 & 16.3 & 1.45 & 77 & 60 & 118 & 5.7 & 53 \\
\hline $6 \mathrm{FDA}^{-D A B A}{ }^{\text {a) }}$ & 49 & 0.42 & 2.86 & 0.15 & 11.1 & 115 & 327 & 6.7 & 72 \\
\hline PIM-6FDA-OH ${ }^{\text {b) }}$ & 228 & 7.15 & 33.6 & 5.3 & 168 & 32 & 43 & 4.7 & 32 \\
\hline Co- $80 / 20^{\text {b) }}$ & 380 & 10.2 & 49.1 & 6.7 & 261 & 37 & 57 & 4.8 & 39 \\
\hline $\mathrm{Co}-50 / 50^{\mathrm{b})}$ & 155 & 2.5 & 14.5 & 1.3 & 67 & 62 & 119 & 5.8 & 52 \\
\hline
\end{tabular}

a) The polymer films were heated at $250{ }^{\circ} \mathrm{C}$ under vacuum for $24 \mathrm{hrs} .{ }^{\text {b) }}$ The polymer films were heated at $300{ }^{\circ} \mathrm{C}$ for $1 \mathrm{hr}$ under nitrogen. 


\section{Table of Contents}

An intrinsically microporous co-polyimide was synthesized by condensation reaction of 4,4'(hexafluoroisopropylidene)diphthalic anhydride (6FDA) with 80 mol\% 3,3,3',3'-tetramethyl1,1'-spirobisindane-5,5'-diamino-6,6'-diol (SBIDA) and $20 \mathrm{~mol} \%$ 3,5-diaminobenzoic acid (DABA) Unexpectedly, the copolymer not only demonstrated higher microporosity (300 $\mathrm{m}^{2} / \mathrm{g}$ ) than the 6FDA-SBIDA (PIM-6FDA-OH) homopolymer $\left(190 \mathrm{~m}^{2} / \mathrm{g}\right)$, but exhibited simultaneously enhanced $\mathrm{CO}_{2}$ permeability (from 119 to 171 Barrer) and $\mathrm{CO}_{2} / \mathrm{CH}_{4}$ selectivity (from 35 to 41 ) after thermal annealing at $250{ }^{\circ} \mathrm{C}$. In-situ solid-state esterification reaction of $\mathrm{OH}$ (from SBIDA) and $\mathrm{COOH}$ (from DABA) at $300{ }^{\circ} \mathrm{C}$ resulted in crosslinking of the copolyimide that further enhanced the $\mathrm{CO}_{2}$ permeability to 261 Barrer with almost unchanged selectivity. 